\title{
Career Advancement: Microscopy Technician to Core Facility Director
}

Frank P. Macaluso 1,2,3

1. Analytical Imaging Facility, Albert Einstein College of Medicine, Bronx, NY, USA.

2. Department of Anatomy and Structural Biology, A. Einstein College of Medicine, Bronx, NY, USA.

3. Gruss-Lipper Biophotonics Center, Albert Einstein College of Medicine, Bronx, NY, USA

In order to maximize your career development and advancement, it is important to evaluate where you want to go and how to get there at an early stage. As a laboratory technician, there are many options to pursue, one of them is advancing to become a Core Facility Director. This presentation will offer suggestions to turn your lab job into a career as a Core Facility Director.

In an academic setting, Facility Directors are often non-tenure track faculty. One of the criteria to be eligible to become faculty is an advanced degree, as a minimum a Master's Degree and sometimes a Ph. D. is required for these faculty appointments. Your degree can be in any related subject area. Regardless of the advanced degree you hold, working as a technician in a core facility will place you in a very good position to advance to core director.

In order to be successful in this career track, you must be passionate about microscopy and become a true imaging expert. In addition to the expertise you will develop as a technician, this can be accomplished by enrolling in a degree granting program [1] or attending individual workshops and courses at or near your place of employment. Vendors often offer free workshops to introduce the latest equipment. Your expertise can be further enhanced by attending seminars to learn how researchers apply imaging technology, and by learning and developing advanced techniques after you master the basics. On the job, your work ethic will shine through based on your passion and willingness to tackle difficult projects.

Another aspect of advancing your career path involves joining professional societies for networking and learning. For a microscopist, the Microscopy Society of America (MSA) and your Local Affiliated Society of MSA are ways to be connected to a network of experts. You should try to negotiate funding from your employer to attend meetings, as a mechanism to advance your individual skills but also to bring new developments back to your lab. MSA offers incentives for technologists to obtain funding support to attend Microscopy and Microanalysis (M\&M): you can submit a poster and apply for a Professional Technical Staff award from the Technologists Forum. Attending society meetings will also give you an opportunity to speak with the vendors on the exhibit floor. They are eager to explain the intricacies of the latest technological advances they offer to the microscopy community. Another way to add to your credentials as an expert microscopist is to earn the Certified Electron Microscopy Technologist (CEMT) designation from the MSA Certification Board [2, 3]. Further technical training can be achieved by enrolling in M\&M pre-meeting workshops for in-depth training on cutting-edge technologies. 
In addition to your imaging expertise, there are a number of skills that you will need to develop to be a successful Core Director. Directing a core is like running a small business. You must work with a large diverse user group. You must devote considerable effort to customer service. You will be required to establish an operating budget and to work within it. Taking a business course may be of benefit to you. As a technician, you can get involved in billing, inventory control and ordering of supplies to get a taste of the management aspect of the facility. You must demonstrate a willingness to introduce new technologies to your facility. This may entail writing Shared Equipment Grants (a full topic in itself) [4] or raising funds from internal sources. You will be required to hire and manage a technical staff. Advice and assistance from your Human Resources department will help you navigate here. As a senior technician, training newly hired technicians will prime you for training/supervising an entire staff. Take advantage of opportunities to teach in a more formal setting. Give a lecture in a microscopy course or offer a workshop on an area of your expertise to gain confidence in your presentation skills.

Directing a Core Facility is a challenging yet rewarding career position. As you explore this career track, speak with core facility directors. Most are willing to share the pros and cons of their position and offer advice regarding negotiating the path towards your successful professional career. [5, 6]

[1] San Joaquin Delta College http://www.deltacollege.edu/program/electron-microscopy

[2] MSA Tech Forum CEMT https://www.microscopy.org/education/programs.cfm

[3] Kysar, P., Calomeni, E. Microsc. Microanal. 20 (Suppl 3), 2014:2048

[4] Macaluso, F. P., Microsc. Microanal. 24 (Suppl 1), 2018: 2336

[5] The author would like to thank Dr. Vera DesMarais for help in editing this manuscript.

[6] The Analytical Imaging Facility is funded by NCI Cancer Grant P30CA013330. 